\title{
Regulation of shear-induced nuclear translocation of the Nrf2 transcription factor in endothelial cells Chung-Yu Hsieh ${ }^{\dagger 1,2}$, Huai-Yu Hsiao ${ }^{\dagger 1}$, Wan-Yi Wu${ }^{1}$, Ching-Ann Liu ${ }^{2}$, Yu- Chih Tsai ${ }^{2}$, Yuen-Jen Chao ${ }^{2}$, Danny L Wang${ }^{2}$ and Hsyue-Jen Hsieh*1
}

\author{
Address: ${ }^{1}$ Department of Chemical Engineering, National Taiwan University, Taipei 106, Taiwan and ${ }^{2}$ Institute of Biomedical Sciences, Academia \\ Sinica, Taipei 115, Taiwan \\ Email: Chung-Yu Hsieh -r94524008@ntu.edu.tw; Huai-Yu Hsiao - r90524030@ntu.edu.tw; Wan-Yi Wu - r92524011@ntu.edu.tw; Ching- \\ Ann Liu - sagi@gate.sinica.edu.tw; Yu-Chih Tsai - mike@ibms.sinica.edu.tw; Yuen-Jen Chao - yjchao@ibms.sinica.edu.tw; \\ Danny L Wang - lingwang@ibms.sinica.edu.tw; Hsyue-Jen Hsieh* - hjhsieh@ntu.edu.tw \\ * Corresponding author †Equal contributors
}

Published: 22 January 2009

Journal of Biomedical Science 2009, 16:12 doi:10.1 186/1423-0127-16-12

This article is available from: http://www.jbiomedsci.com/content/16/1/12

(c) 2009 Hsieh et al; licensee BioMed Central Ltd.

This is an Open Access article distributed under the terms of the Creative Commons Attribution License (http://creativecommons.org/licenses/by/2.0), which permits unrestricted use, distribution, and reproduction in any medium, provided the original work is properly cited.
Received: 28 August 2007

Accepted: 22 January 2009

\begin{abstract}
Background: Vascular endothelial cells (ECs) constantly experience fluid shear stresses generated by blood flow. Laminar flow is known to produce atheroprotective effects on ECs. Nrf2 is a transcription factor that is essential for the antioxidant response element (ARE)-mediated induction of genes such as heme-oxygenase I (HO-I). We previously showed that fluid shear stress increases intracellular reactive oxygen species (ROS) in ECs. Moreover, oxidants are known to stimulate Nrf2. We thus examined the regulation of $\mathrm{Nrf2}$ in cultured human ECs by shear stress.

Results: Exposure of human umbilical vein endothelial cells (HUVECs) to laminar shear stress (I2 dyne/ $\mathrm{cm}^{2}$ ) induced Nrf2 nuclear translocation, which was inhibited by a phosphatidylinositol 3kinase (PI3K) inhibitor, a protein kinase $\mathrm{C}$ (PKC) inhibitor, and an antioxidant agent $\mathrm{N}$-acetyl cysteine (NAC), but not by other protein kinase inhibitors. Therefore, PI3K, PKC, and ROS are involved in the signaling pathway that leads to the shear-induced nuclear translocation of $\mathrm{Nrf2}$. We also found that shear stress increased the ARE-binding activity of Nrf2 and the downstream expression of HO-I.
\end{abstract}

Conclusion: Our data suggest that the atheroprotective effect of laminar flow is partially attributed to Nrf2 activation which results in ARE-mediated gene transcriptions, such as HO-I expression, that are beneficial to the cardiovascular system.

\section{Background}

Vascular endothelial cells (ECs) are in direct contact with blood flow and are constantly exposed to blood flow-generated shear stresses. Accumulated data in the literature reveal that laminar shear stress is beneficial for the endothelium [1]. Numerous studies and accumulating microarray data [2-5] indicate that physiological shear stresses produce antioxidant [6], antiapoptotic [7], anti- inflammatory [8], and antiproliferative effects [9,10]. Investigations from our laboratories and others have shown that shear stress inhibits serum-, cytokine-, and hydrogen peroxide-induced responses [11-14]. Shear stresses also initiate cascades of events that are essential for endothelial function. For example, shear stress can stimulate phosphatidylinositol 3-kinase (PI3K) activity [15] which is required for Akt phosphorylation; this helps 
prevent endothelial apoptosis [7] and contributes to endothelial nitric oxide synthase (eNOS) activation and subsequent nitric oxide (NO) production [16,17]. NO acts as a vasodilator and exerts atheroprotective effects on the endothelium by inhibiting many atherosclerosisprone events [18-21]. Moreover, a number of antioxidant genes, such as heme-oxygenase 1 (HO-1), NAD(P)H:quinine oxidoreductase-1, and glutathione S-transferase, are upregulated in ECs under laminar shear stress, and the antioxidant response element (ARE) which resides in the promoter regions of these antioxidant genes plays a vital role in their induction [6]. Upregulation of the antioxidant, superoxide dismutase (SOD), by shear stresses can suppress the apoptotic effects induced by other agents [22]. However, the detailed mechanisms of how the antioxidant ability of shear stresses is regulated remain to be elucidated.

Nuclear factor erythroid 2-related factor 2 (Nrf2) is a cap'n'collar (CNC) basic leucine zipper transcription factor [23]. Evidence compiled from in vitro and in vivo studies has shown that Nrf2 is essential for ARE-mediated induction of genes including phase II detoxifying enzymes and antioxidant enzymes [24-26]. Results obtained from experiments exploiting Nrf2-null mice suggest that Nrf2 plays a protective role against xenobiotics, oxidative stress, and cardiovascular injuries [26-28]. A recent study revealed that Nrf2 activation inhibits inflammatory gene expression [29]. The N-terminal domain of $\mathrm{Nrf} 2$ is bound to the cytoskeletal-associated protein, Keap1, that negatively regulates Nrf2 by both repressing Nrf2 transcriptional activity [30] and enhancing its rate of proteasomal degradation [31,32] in the cytoplasm. Upon stimulation, Nrf2 dissociates from Keap1 and is translocated into the nucleus to initiate the following transcriptional events [30]. Oxidants and electrophiles are known to stimulate Nrf2 $[33,34]$, and herein we show that hydrogen peroxide $\left(\mathrm{H}_{2} \mathrm{O}_{2}\right)$, a major reactive oxygen species (ROS), is another Nrf2 stimulator. A recent study demonstrated that NO also induces Nrf2 nuclear translocation [35]. So far, knowledge of the regulatory mechanisms of Nrf2 activation is very limited. Several studies implied that PI3K is a key regulator of $\mathrm{Nrf} 2[36,37]$. It was also found that protein kinase $\mathrm{C}$ (PKC) phosphorylates Nrf2 and regulates concomitant ARE-mediated transcription in response to oxidative stress [38,39]. Mitogen-activated protein kinases (MAPKs), such as ERK1/2 and p38, are also reported to modulate Nrf2 activation [40,41]. Although the signaling pathways of the translocation of Nrf2 were reported in several previous papers $[42,43]$, studies on the signaling pathway of Nrf2 translocation under shear stress stimulation are very limited. Hosoya et al. reported that both laminar and oscillatory shear stresses can trigger the translocation of Nrf2, but only laminar shear stresses can induce Nrf2 binding to the ARE
[44]. In this study, we investigated the signaling pathways involved in shear stress-induced Nrf2 translocation.

In a previous study, we showed that shear stress increases intracellular ROS and antioxidant activity in ECs [45]. Generation of ROS may participate in cellular responses and signal transduction. Shear-induced ROS are responsible for inducing HO-1, that has remarkable antioxidant abilities and carries out diverse protective functions in diseases such as atherosclerosis [46-48]. In the present study, we examined the regulatory mechanisms of shear stress on the Nrf2 transcription factor and its downstream target, HO-1, in cultured human umbilical vein endothelial cells (HUVECs). We demonstrated that shear stress induced Nrf2 nuclear translocation, and this process involved PI3K, ROS, and PKC. We also showed that shear stress increased the ARE-binding activity of Nrf2. Parallel experiments using $\mathrm{H}_{2} \mathrm{O}_{2}$ to stimulate ECs were carried out, and similar results were obtained. Our data suggest that in some way, the atheroprotective role of laminar shear stress may be attributed to Nrf2 activation which results in initiation of ARE-mediated gene transcription, including HO-1 expression, that is beneficial to the cardiovascular system.

\section{Materials and methods \\ Cell culture}

Primary cultures of HUVECs were harvested from umbilical cord veins by collagenase isolation. The harvested cells were resuspended in culture medium (Medium 199 supplemented with $20 \%$ fetal bovine serum (FBS)), plated on $10-\mathrm{cm}$ culture dishes, and then incubated at $37^{\circ} \mathrm{C}$ in $5 \%$ $\mathrm{CO}_{2}$ balanced with air. The following day, HUVECs were rinsed with buffer and grown to confluence within 2 to 3 days. The cells were subcultured on fibronectin-coated glass slides. One day prior to the shear stress experiments, the concentration of FBS in the culture medium was reduced to $2 \%$, and this was used throughout the shear stress experiments.

\section{Shear stress experiments}

Exposure of HUVECs to shear stress was conducted in a parallel-plate flow chamber as previously described [49]. Continuous flow of culture medium through the flow chamber was generated by a roller pump. The flow loop system was maintained at $37^{\circ} \mathrm{C}$. The $\mathrm{pH}$ of the medium was maintained at a constant level by continuous gassing of the medium reservoir with humidified $5 \% \mathrm{CO}_{2}$ balanced with air.

\section{Nuclear protein extraction}

To prepare nuclear protein extracts, HUVECs were washed with cold phosphate-buffered saline (PBS) and then removed by scraping in detachment buffer $(150 \mathrm{mM}$ $\mathrm{NaCl}, 1 \mathrm{mM}$ EDTA, and $40 \mathrm{mM}$ Tris; pH 7.6). After centrif- 
ugation of the cell suspension at $2000 \mathrm{rpm}$, the cell pellets were resuspended in cold buffer A containing $\mathrm{KCl}(10$ $\mathrm{mM})$, EDTA $(0.1 \mathrm{mM})$, dithiothreitol $(1 \mathrm{mM})$, and phenylmethylsulfonyl fluoride $(1 \mathrm{mM})$ for $15 \mathrm{~min}$. The cells were lysed by adding $10 \%$ Nonidet P-40 and then centrifuged at $6000 \mathrm{rpm}$ to obtain a pellet of nuclei. The pelleted nuclei were resuspended in cold buffer B containing HEPES $(20 \mathrm{mM})$, EDTA $(1 \mathrm{mM})$, dithiothreitol $(1 \mathrm{mM})$, and phenylmethylsulfonyl fluoride $(1 \mathrm{mM})$, as well as $\mathrm{NaCl}(0.4 \mathrm{mM})$, and then vigorously agitated from time to time, followed by centrifugation. The supernatant containing the nuclear proteins was used for Western blot analysis or an electrophoretic mobility shift assay (EMSA).

\section{Western blot analysis}

Proteins were extracted in sodium dodecylsulfate (SDS) buffer and analyzed by SDS-polyacrylamide gel electrophoresis (SDS-PAGE). After being transferred onto a nitrocellulose membrane, antigens were analyzed by specific antibodies. Antigen-antibody complexes were detected using an ECL detection system (Pierce).

\section{Reverse-transcriptase polymerase chain reaction (RT- PCR)}

The primer of Nrf2 (GenBank accession no.: BC011558) was designed using the GCG system, and the GADPH primer was provided by Dr. H. H. Chen (Institute of Biomedical Sciences, Academia Sinica, Taiwan). Nrf2 primers were synthesized by MB Mission Biotech (Taipei, Taiwan) and consisted of 5'-ACA CGG TCC ACA GCT CAT CAT-3' (forward) and 5'-TTG GCT TCT GGA CTT GGA AC-3' (reverse); GAPDH primers were synthesized by the same company and consisted of 5'-TGG TAT CGT GGA AGG ACT CAT GAC-3' (forward) and 5'-ATG CCA GTG AGC TTC CCG TTC AGC-3' (reverse). When total RNA was isolated from HUVECs, a Superscript III one-step RT-PCR kit was used for the reverse transcription. After 25 cycles, the end products were subjected to $1 \%$ agarose electrophoresis to analyze the target RT-PCR products.

\section{Electrophoretic mobility shift assay (EMSA)}

The supernatant containing the nuclear proteins was used for the EMSA. The probe for EMSA was a synthetic 24-mer oligonucleotide (5'-GGG ACT GGT GAC TCA GCA AAA TCT-3') containing the ARE binding site within the promoter region and about $4 \mathrm{~kb}$ upstream of the human HO1 gene [6]. The probe was end-labeled with biotin using the Biotin 3'-end DNA labeling kit from Pierce (Rockford, IL). Both the sense and antisense oligonucleotides were separately labeled and then annealed to form the doublestranded probe. $10 \mu \mathrm{g}$ of the nuclear protein from either untreated or the different stress-exposed cells was incubated at room temperature for $20 \mathrm{~min}$ in binding reaction buffer containing the biotin-labeled 24-mer probe with, or without, an unlabeled competitor. The competitor used was the unlabeled 24-mer just described or the biotin control probe (Pierce). In the antibody supershift assay, the anti-Nrf2 antibody ( $1 \mu \mathrm{g}$, Santa Cruz Biotechnology) was incubated with the mixture for $20 \mathrm{~min}$ at room temperature followed by the addition of the biotin-labeled DNA probe. Proteins in the reaction mixture were then separated by electrophoresis in a 5\% TBE polyacrylamide gel (Bio-Rad), run at $100 \mathrm{~V}$ for $45 \mathrm{~min}$. Protein-DNA complexes were transferred to a positively charged nylon membrane (Bio-Rad) at $100 \mathrm{~V}$ for $60 \mathrm{~min}$ with $0.5 \% \mathrm{TBE}$ buffer at $4^{\circ} \mathrm{C}$. The transferred DNA was cross-linked to the membrane by 60-s exposure to ultraviolet light. Biotinlabeled DNA was detected by using the LightShift chemiluminescent EMSA kit (Pierce) following the manufacturer's instructions.

\section{Results \\ Shear stress increases Nrf2 expression and nuclear translocation}

To examine the effect of shear stress on Nrf2 expression and activation, HUVECs were exposed to a laminar shear stress of 12 dyne $/ \mathrm{cm}^{2}$ which resembles physiological blood flow conditions in atherosclerotic plaque-free regions. Shear stress substantially increased the total cellular levels of Nrf2 protein over time (Figure 1A). Despite the fact that the predicted molecular weight of Nrf2 is 66 $\mathrm{kD}$, the major Nrf2 band detected by immunoblotting appeared to be approximately $100 \mathrm{kDa}$ as seen in Figure $1 \mathrm{~A}$, similar to results reported in previous studies $[50,51]$.

It had been reported that Nrf2 binds to the cytoskeletonassociated protein, Keap1, in cytoplasm under basal conditions and then is translocated into the nucleus upon stimulation [30]. Herein, we investigated the regulation of Nrf2 activation by shear stress. The nuclear level of Nrf2 protein increased with respect to time in HUVECs subjected to shear stress (Figure $1 \mathrm{~B}$ ), revealing that shear stress induced Nrf2 nuclear translocation, and thus could initiate downstream transcription activities.

Since mRNA of Nrf2 is constitutively expressed in cells [52], we also investigated the mRNA of Nrf2 and found that it exhibited higher expression under shear stress stimulation (Figure 1C). As revealed by RT-PCR, Nrf2 mRNA was elevated after 30 min of shear stress, and reached a maximum at around $60 \mathrm{~min}$. The expression of Nrf2 mRNA was reduced after 120 min of shear stress, but it was still higher than the basal static condition. The results show that shear stress not only induces Nrf2 translocation but also increases the expression of Nrf2 at the mRNA and protein levels. 
A

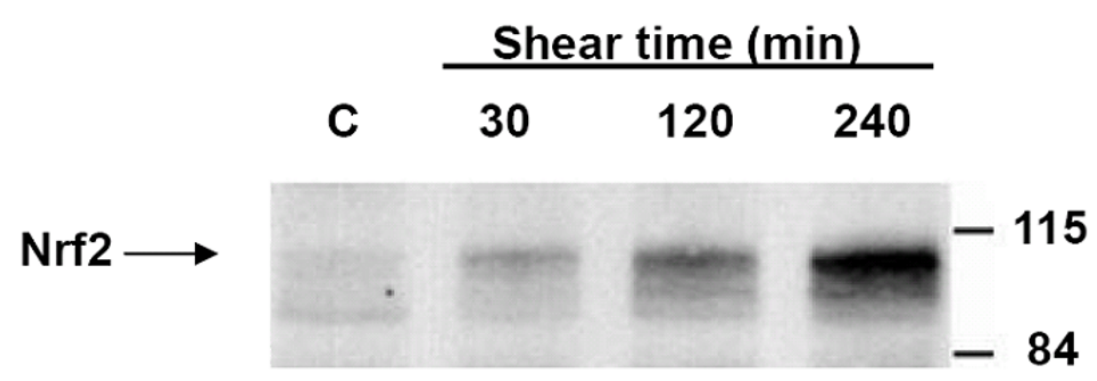

Tubulin

B



C

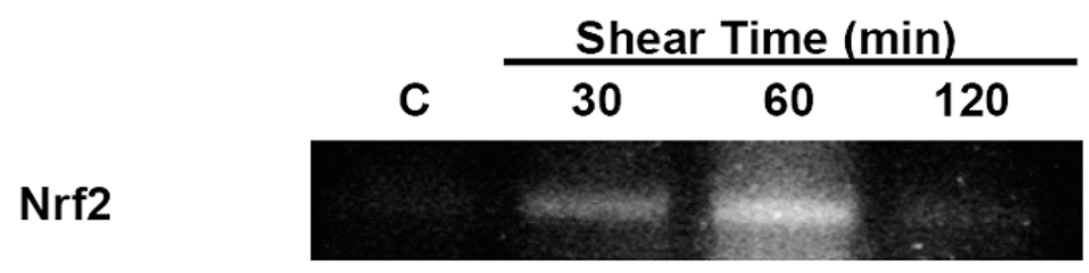

\section{GAPDH}



Figure I

Shear stress increases Nrf2 protein expression and induces Nrf2 translocation into nuclei. (A) Shear stress increased the total amount of Nrf2 protein. Human umbilical vein endothelial cells (HUVECs) were exposed to laminar shear stress at a magnitude of $12 \mathrm{dyne} / \mathrm{cm}^{2}$ for the indicated times. Total cell lysates were recovered and subjected to Western blot analysis with anti-Nrf2 and anti-tubulin (internal control, used to indicate equal loading of protein in each lane) antibodies. (B) Shear stress triggered the translocation and accumulation of Nrf2 protein in nuclei. HUVECs were exposed to laminar shear stress $\left(12\right.$ dyne/ $\left.\mathrm{cm}^{2}\right)$ for the indicated times. Nuclear extracts were isolated and subjected to Western blotting with anti-Nrf2 and anti-nucleolin (internal control) antibodies. (C) Shear stress increased Nrf2 mRNA. HUVECs were exposed to laminar shear stress ( 12 dyne/cm${ }^{2}$ ) for the indicated times. Total RNA was isolated, and Nrf2 and GAPDH (internal control) mRNA levels were detected by RT-PCR. Results are representative of three independent experiments. 


\section{Shear stress induces Nrf2 nuclear translocation through a PI3K-dependent pathway}

Many previous studies implied that Nrf2 activation is mediated through the PI3K pathway $[36,37,53]$. Since shear stress is known to activate the PI3K pathway, we speculated that PI3K might participate in shear-induced Nrf2 nuclear translocation. As anticipated, we found that shear-induced Nrf2 nuclear translocation was suppressed by pretreating HUVECs with LY294002, a PI3K inhibitor (Figure 2A), suggesting that the PI3K pathway plays a key role in shear-induced Nrf2 activation.

It was found that protein kinase $\mathrm{C}$ (PKC) phosphorylates Nrf2 and regulates concomitant ARE-mediated transcription in response to oxidative stress $[38,39]$. A recent study showed that the anti-inflammatory activity of Phellinus linteus (an orange-colored mushroom) is mediated through PKCdelta/Nrf2/ARE signaling that leads to the upregulation of HO-1 [54]. These findings suggest that PKC may play a role in shear-induced Nrf2 nuclear translocation. To test this hypothesis, calphostin C (a PKC inhibitor) was used to pretreat HUVECs prior to the shear stress experiment. Pre-exposure to calphostin C did not affect the basal level of nuclear Nrf2 protein but significantly attenuated shear-induced Nrf2 nuclear translocation (Figure 2B), indicating that PKC is involved in the nuclear translocation of Nrf2 in response to shear stress.

Chen et al. determined that dietary chemopreventive compounds induce Nrf2 translocation through MAPK pathways [55]. Owuor et al. also reported similar pathways for Nrf2 translocation under chemical stress [56]. Many MAPK family proteins, including p38 and JNK, are activated by shear stress stimulation. It is likely that the translocation of Nrf2 under shear stress conditions is regulated by the MAPK pathway. However, the use of SB203580 (a p38-specific inhibitor) and SP600125 (a JNK inhibitor) did not attenuate the translocation of Nrf2 (Figs. 2C \&2D). This suggests that even though MAPK pathways are activated by shear stress, p38 and JNK are not involved in shear-induced Nrf2 translocation.

\section{Shear stress increases Nrf2 nuclear accumulation and binding activity to ARE through ROS}

In a previous study we showed that shear stress increases intracellular ROS which participate in cellular responses and signal transduction in endothelial cells [45]. Since Nrf2 is a gene that can be stimulated by oxidants and electrophiles $[33,34]$, we also speculated that ROS might participate in shear-induced Nrf2 nuclear translocation. We found that shear-induced Nrf2 nuclear translocation could be suppressed by pretreating endothelial cells with $\mathrm{N}$-acetyl cysteine (NAC), an ROS scavenger, suggesting that ROS are essential for shear-induced Nrf2 activation (Figure 3). We also found that pretreating cells with NAC had an inhibitory effect on Nrf2 mRNA and protein levels (data not shown).

On the other hand, a recent study demonstrated that NO can also induce Nrf2 nuclear translocation [35]. It is known that shear stresses increase NO production in endothelial cells $[57,58]$. We thus investigated if NO plays any role in shear-induced Nrf2 nuclear translocation. Using eNOS inhibitors (L-NAME and L-NNA) to block NO production in endothelial cells, no effect was seen on shear-induced Nrf2 nuclear translocation (Figures 4A \&4B). Our results thus indicate that shear-increased NO production is unimportant for the nuclear translocation of Nrf2 induced by shear stress.

Nrf2 is a transcription factor that is essential for the AREmediated induction of many redox-sensitive genes including HO-1. To investigate the effect of shear stress on the ARE-binding activity of $\mathrm{Nrf} 2$, nuclear proteins were isolated from endothelial cells and used for an EMSA. An oligonucleotide (5'-GGG ACT GGT GAC TCA GCA AAA TCT$\left.3^{\prime}\right)$ containing the ARE-binding site within the promoter region lying about $4 \mathrm{~kb}$ upstream of human HO-1 gene was used as a probe in the EMSA $[6,59]$. In the antibody supershift assay, the anti-Nrf2 antibody was incubated with nuclear proteins prior to the addition of the oligonucleotide. The results indicated that shear stress enhanced Nrf2 binding activity to ARE, and this effect was significantly repressed by the ROS scavenger, NAC (Figure 5). Similarly, $\mathrm{H}_{2} \mathrm{O}_{2}$ also increased the ARE-binding activity of $\mathrm{Nrf2}$, and this event was significantly suppressed by NAC (Figure 5). Based on these findings, it is suggested that shear stress promotes the binding activity of Nrf2 to ARE through ROS.

\section{Shear stress and $\mathrm{H}_{2} \mathrm{O}_{2}$ induce $\mathrm{HO}-\mathrm{I}$ protein expression through the PI3K pathway}

As presented earlier, PI3K plays a vital role in shearinduced Nrf2 activation (Figure 2). Activated Nrf2 was demonstrated to bind to an ARE-containing oligonucleotide probe (Figure 5), and this might trigger the expression of ARE-containing genes including HO-1. As expected, shear stress increased $\mathrm{HO}-1$ protein levels in HUVECs in a time-dependent manner (Figure 6A), and this event was significantly suppressed by pretreating HUVECs with LY294002 (a PI3K inhibitor), thus indicating an essential role of $\mathrm{PI} 3 \mathrm{~K}$ in shear-induced $\mathrm{HO}-1$ protein expression (Figure $6 \mathrm{~B}$ ). $\mathrm{H}_{2} \mathrm{O}_{2}$ also increased $\mathrm{HO}-1$ protein levels in a time-dependent manner (Figure 6C), and it was significantly repressed by pretreating HUVECs with LY294002 (a PI3K inhibitor), indicating that PI3K also plays a key role in $\mathrm{H}_{2} \mathrm{O}_{2}$-induced $\mathrm{HO}-1$ protein expression (Figure 6D). Taken together, our data suggest that shear stress and hydrogen peroxide both induce HO1 protein expression through the PI3K pathway. 
A

$\begin{array}{ccccc}\text { Shear stress } & - & + & + & - \\ \text { LY294002 } & - & - & + & +\end{array}$

\section{Nuclear Nrf2}

Tubulin

B

$\begin{array}{lllll}\text { Shear Stress } & - & + & - & + \\ \text { Calphostin C } & - & - & + & +\end{array}$

\section{Nuclear Nrf2}

Nucleolin



C

$\begin{array}{ccccc}\text { Shear Stress } & - & + & + & - \\ \text { SB203580 } & - & - & + & +\end{array}$

Nuclear Nrf2

$\alpha \mathrm{C23}$

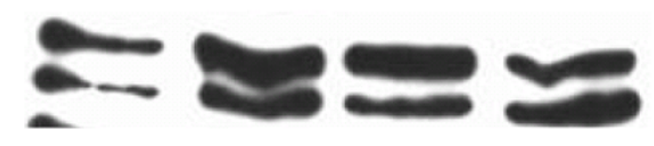

D

$\begin{array}{ccccc}\text { Shear Stress } & - & + & + & - \\ \text { SP600125 } & - & - & + & +\end{array}$

Nuclear Nrf2

$\alpha C 23$

Figure 2 (see legend on next page) 
Figure 2 (see previous page)

PI3K is involved in shear-induced Nrf2 nuclear translocation. (A) PI3K is involved in shear-induced translocation of Nrf2 into nuclei. HUVECs were pretreated with LY294002, a PI3K inhibitor (50 $\mu$ M), for 60 min and then kept as static controls or exposed to laminar shear stress (I 2 dyne $\left./ \mathrm{cm}^{2}\right)$ in the presence of LY294002 for I 20 min. Nuclear extracts were prepared and subjected to Western blotting with an anti-Nrf2 antibody. The cytoplasmic fractions were subjected to Western blotting with an anti-tubulin (internal control) antibody. (B) PKC is involved in Nrf2 activation. HUVECs were pretreated with calphostin C, a PKC inhibitor (200 nM), or DMSO as a negative control for $30 \mathrm{~min}$, and then exposed to laminar shear stress $\left(12\right.$ dyne $\left./ \mathrm{cm}^{2}\right)$ or kept in a static condition for $2 \mathrm{~h}$. After treatment, nuclear extracts were prepared and subjected to SDSPAGE and immunoblotted with anti-Nrf2 and anti-nucleolin (internal control) antibodies. Similar results were obtained from repeated experiments. (C) p38 is not involved in shear-induced Nrf2 translocation. HUVECs were pretreated with SB203580, a p38 inhibitor (10 $\mu \mathrm{M})$, for $30 \mathrm{~min}$, and then kept as a static control or exposed to shear stress in the presence of inhibitors for $60 \mathrm{~min}$. Nuclear extracts were prepared and subjected to Western blotting with anti-Nrf2 and anti- $\alpha \mathrm{C} 23$ (internal control) antibodies. Similar results were obtained from repeated experiments. (D) JNK is not involved in shear-induced Nrf2 translocation. HUVECs were pretreated with SP600I25, a JNK inhibitor (I0 $\mu \mathrm{M})$, for 60 min, and then kept as a static control or exposed to shear stress in the presence of the inhibitor for $60 \mathrm{~min}$. Nuclear extracts were prepared and subjected to Western blotting with anti-Nrf2 and anti- $\alpha$ C23 (internal control) antibodies. Similar results were obtained from repeated experiments.

\section{Discussion}

In the present study, we examined the regulatory mechanisms of shear stress on the Nrf2 transcription factor and its downstream target, HO-1, in HUVECs. It was found that shear stress activated Nrf2 nuclear translocation and increased the amount of Nrf2 protein and the level of mRNA transcription (Figure 1). The translocation of Nrf2 occurred after 10 min of shear stress, suggesting that Nrf2 translocation which induces downstream gene regulation is a rapid response. However, the mRNA level of Nrf2 increased obviously after $30 \mathrm{~min}$ of shear stress and reached a maximum at around $60 \mathrm{~min}$. Hong et al. and Eggler et al. reported that under a basal condition, Nrf2 undergoes Cul3-dependent ubiquitination and proteosomal degradation, but under various stimuli, Keap 1 is ubiquitinated to release Nrf2 into the nucleus [60,61]. It is likely that when HUVECs are exposed to shear stress, the early response is ubiquitination of Keap 1 which induces $\mathrm{Nrf} 2$ translocation. Nuclear translocation may decrease the concentration of Nrf2 in the cytosol thus trig-

\section{Shear stress NAC}

\section{Nuclear Nrf2}

\section{Nucleolin}


\section{Figure 3}

ROS are necessary for Nrf2 nuclear translocation. HUVECs were pretreated with NAC, a reactive oxygen species (ROS) scavenger ( $10 \mathrm{mM})$, for $30 \mathrm{~min}$ and then kept as a static control or exposed to shear stress $\left(12 \mathrm{dyne} / \mathrm{cm}^{2}\right)$ in the presence of NAC for 30 min. Nuclear extracts were prepared and subjected to Western blotting with anti-Nrf2 and anti-nucleolin (internal control) antibodies. Similar results were obtained from repeated experiments. 
A

\title{
Shear stress L-NAME
}

\author{
Nuclear Nrf2
}

\author{
Nucleolin
}

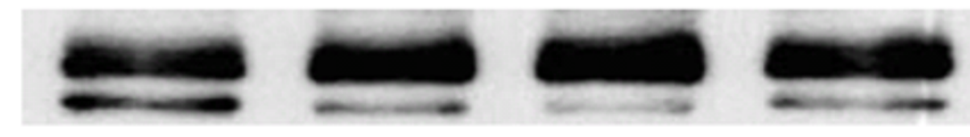

\section{Shear stress \\ L-NNA}

\section{Nuclear Nrf2}

\section{Nucleolin}

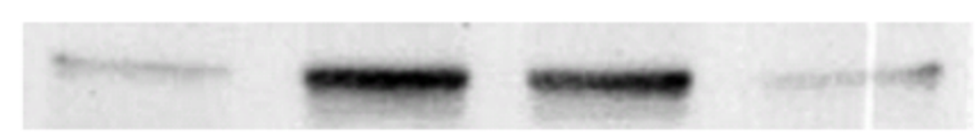

B

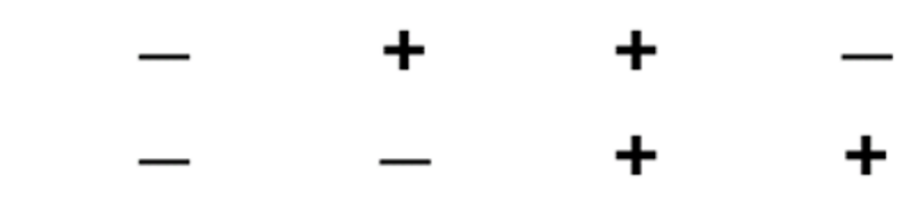





Figure 5

Shear stress increases the antioxidant response element (ARE)-binding activity of Nrf2 through reactive oxygen species (ROS). HUVECs were kept in a static condition (Control), exposed to shear stress (SS) of $12 \mathrm{dyne} / \mathrm{cm}^{2} \mathrm{for} 2 \mathrm{~h}$, incubated with $\mathrm{H}_{2} \mathrm{O}_{2}(200 \mu M)$ for $2 \mathrm{~h}\left(\mathrm{H}_{2} \mathrm{O}_{2}\right)$, or pretreated with NAC (IO mM) (NAC) and then incubated with $\mathrm{H}_{2} \mathrm{O}_{2}(200$ $\mu \mathrm{M})$ for $2 \mathrm{~h}\left(\mathrm{NAC}+\mathrm{H}_{2} \mathrm{O}_{2}\right)$. Before applying the shear stress, HUVECs were pretreated with NAC (I0 mM) for $60 \mathrm{~min}$ and then exposed to shear stress for $2 \mathrm{~h}(\mathrm{NAC}+\mathrm{SS})$. Total nuclear extracts were prepared and analyzed by EMSA using a biotin-labeled oligonucleotide probe containing Nrf2 consensus binding sites corresponding to the HO-I promoter region (5'-GGG ACT GGT GAC TCA GCA AAA TCT-3', within the promoter region lying about $4 \mathrm{~kb}$ upstream of the human HO-I gene). The specificity of the Nrf2 binding was assessed by preincubating nuclear extracts with the biotin-labeled oligonucleotide probe in the presence of $100 \times$ unlabeled oligonucleotide probe to compete for Nrf2 binding (Competition). EMSA performed on the nuclear extracts preincubated with an Nrf2 antibody (SS+Nrf2 Ab) was also included. Results are representative of duplicate experiments with similar results.

dependent. But PI3K is a lipid kinase, and the substrate of PI3K should be a lipid like PIP2, not Nrf2. This implies that the mechanism of $\mathrm{Nrf} 2$ translocation is indirectly mediated by PI3K. There are likely more protein kinase(s) involved in Nrf2 activation, and PKC may be one candidate. When shear stresses activate PI3K, it phosphorylates PIP2 to PIP3, and at this time, phosphoinositide-depend- ent kinase 1 (PDK1) may bind to PIP3 through its $\mathrm{PH}$ domain. PKC, one of the downstream substrates of PDK1, can be phosphorylated and activated. Activation of Nrf2 by PKC possibly occurs through the phosphorylation of S40 at the Neh2 domain of Nrf2, which interacts with Keap1 [38,39]. The phosphorylation of S40 triggers a conformational change in Nrf2, and thus $\mathrm{Nrf} 2$ is released 
A

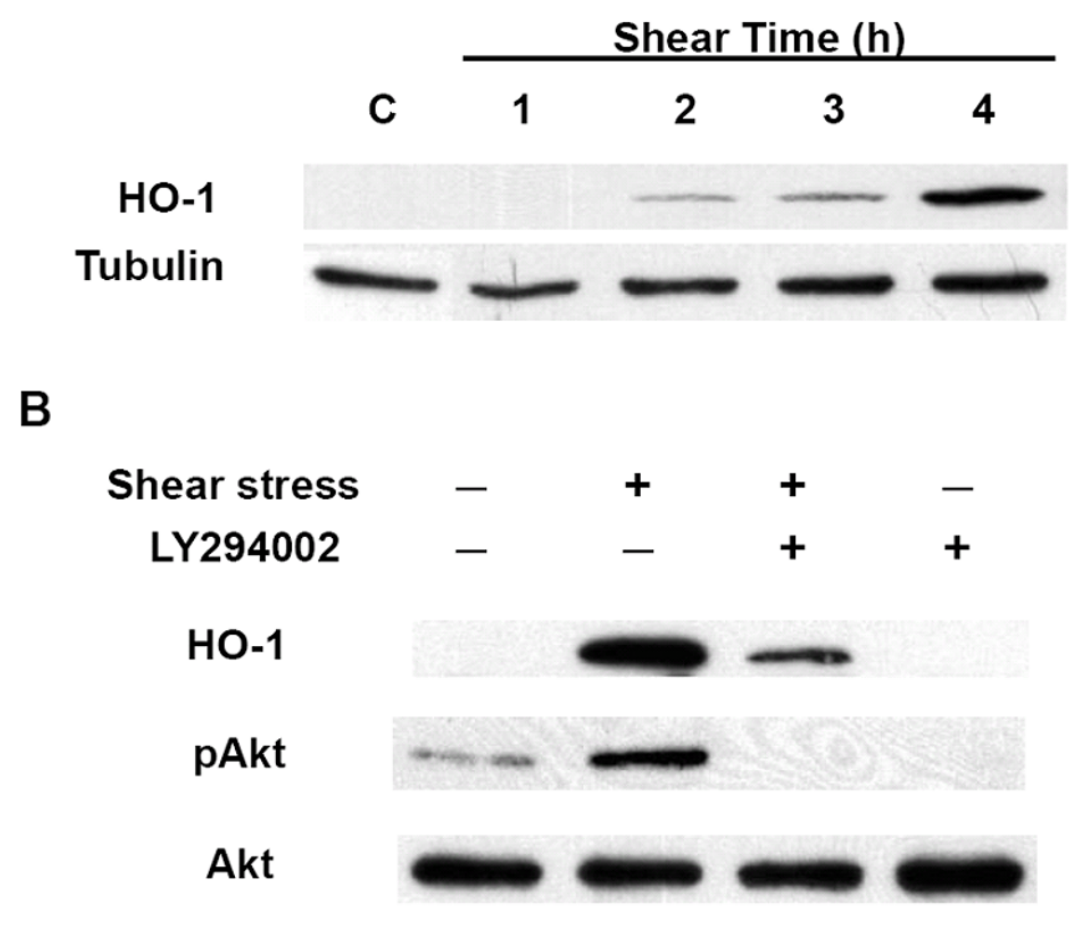

C

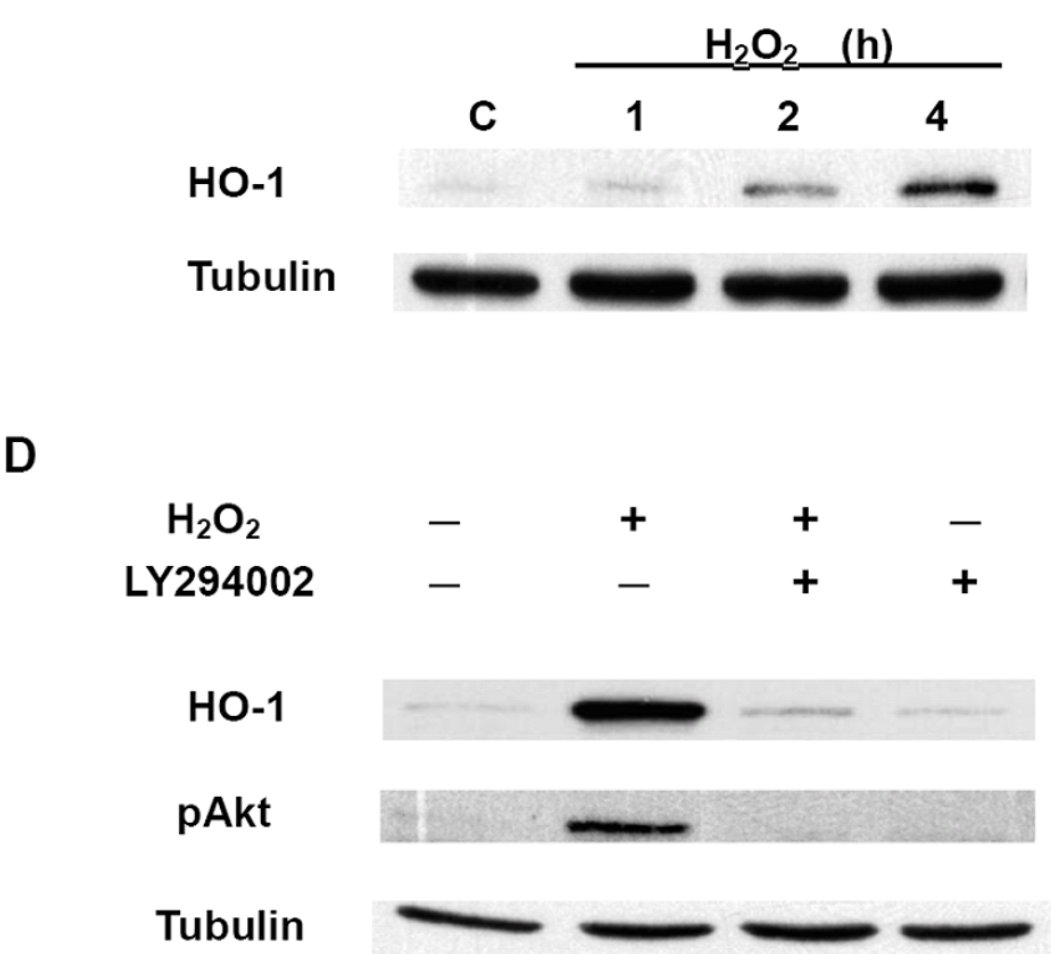

Figure 6 (see legend on next page) 
Figure 6 (see previous page)

Shear stress and hydrogen peroxide induce HO-I expression via a PI3K-dependent pathway. (A) Shear stress increased HO-I protein expression. HUVECs were exposed to laminar shear stress (I 2 dyne $\left./ \mathrm{cm}^{2}\right)$ for the indicated times. After cell lysis, total cell lysates were prepared and subjected to Western blotting with anti-HO-I and anti-tubulin (internal control) antibodies. (B) PI3K is involved in shear-induced HO-I protein expression. HUVECs were pretreated with LY294002, a PI3K inhibitor $(50 \mu \mathrm{M})$ for $60 \mathrm{~min}$ and then kept as static controls or exposed to shear stress in the presence of LY294002 for $4 \mathrm{~h}$. Total cell lysates were subjected to Western blotting with anti-HO-I, anti-phospho-Akt, and anti-Akt (internal control) antibodies. (C) Hydrogen peroxide $\left(\mathrm{H}_{2} \mathrm{O}_{2}\right)$ increased $\mathrm{HO}-\mathrm{I}$ protein expression. $\mathrm{HUVECs}$ were incubated with $\mathrm{H}_{2} \mathrm{O}_{2}(200 \mu M)$ for the indicated times. Total cell lysates were subjected to Western blotting with anti-HO-I and anti-tubulin (internal control) antibodies. (D) $\mathrm{PI} 3 \mathrm{~K}$ is involved in $\mathrm{H}_{2} \mathrm{O}_{2}$-induced $\mathrm{HO}$-I protein expression. HUVECs were either kept as a static control or treated with $\mathrm{H}_{2} \mathrm{O}_{2}(200 \mu \mathrm{M})$ for 4 h or pretreated with LY294002, a PI3K inhibitor (50 $\left.\mu \mathrm{M}\right)$, for 60 min. Total cell lysates were subjected to Western blotting with anti-HO-I, anti-phospho-Akt, and anti-tubulin (internal control) antibodies. Results are representative of duplicate experiments with similar results.

from Keap1. Free Nrf2 in the cytosol is translocated into nuclei or interacts with other protein kinase(s). We speculate that nuclear translocation of $\mathrm{Nrf} 2$ requires either phosphorylation by PKC or another serine or threonine kinase at S40 of the Neh2 domain, which disrupts the interactions of Nrf2 and Keap1, leading to Nrf2 separating from Keap1. With the exception of PI3K, ROS also participate in the nuclear translocation of Nrf2 (Figure 3). However, the detailed mechanism is not clear at the present time. ROS may change the intracellular redox state of HUVECs, triggering the formation of disulfide bonds between the SH groups of cysteine residues within protein molecules, thus altering the activities of those proteins (see discussion below).

In a previous study, we showed that shear stresses increase the amount of ROS in endothelial cells [45]. The generation of ROS may participate in many cellular responses and signal transduction. This study verified that ROS are important regulators of the nuclear translocation of Nrf2. The intracellular redox state of HUVECs can be altered by ROS. On the other hand, many previous studies reported that shear stresses activate eNOS and increases the amount of endogenous NO $[57,58]$, which also affects the intracellular redox state of HUVECs. However, we found that shear-increased NO had no influence on Nrf2 translocation (Figure 4).

The detailed mechanism of the regulation of Nrf2 translocation by the intracellular redox state remains to be elucidated. Wakabayashi et al. showed that both C273 and C288 residues are necessary for Keap1 to repress Nrf2 [62]. Based on our data in Figs. 3 \&4, we speculated that the redox state of HUVECs may influence Nrf2 translocation by changing the redox state of the C273 and C288 residues of Keap1. There might be several possible mechanisms that alter the $\mathrm{C} 273$ and C288 residues of Keap1 and thus release Nrf2. For example, it is possible that when the amount of ROS is increased, the SH groups on C273 and C288 may be oxidized to form disulfide bonds, thus triggering Keap1 to release Nrf2 and initiating Nrf2 nuclear translocation. It was reported that an elevated concentration of xenobiotics in the cytosol causes oxidative stress and induces the dissociation of $\mathrm{Nrf} 2$ from Keap1 through the above-mentioned ROS-mediated mechanism [31]. Another possibility is the nitrosylation of C273 and C288 residues of Keap1 which causes the release of $\mathrm{Nrf2}$, and this mechanism is carried out only when the concentration of $\mathrm{NO}$ in the cytosol is much higher than the basal condition. We speculated that the concentration of shear-induced NO was not high enough to trigger Nrf2 translocation. Thus, it is likely that the ROS-mediated mechanism plays a relatively more important role than the NO-mediated mechanism in regulating Nrf2 translocation.

As for the intracellular sources of ROS, Li et al. and Hancock et al. showed that NADPH oxidases (NOXs) are a major source of ROS $[63,64]$, and in our preliminary study, we found that the use of small interfering (si)RNA against NOX2 repressed Nrf2 translocation (data not shown). This result also supports our deduction that a change in the redox state of HUVECs triggers Nrf2 translocation.

Results obtained from the gel shift assay further revealed that shear stress enhanced the ARE-binding activity of Nrf2 through the involvement of ROS (Figure 5). Shearinduced HO-1 protein expression was also suppressed by a PI3K inhibitor (Figure 6). Parallel experiments were conducted using $\mathrm{H}_{2} \mathrm{O}_{2}$, a major ROS, as the stimulus, and similar results were obtained. These results provide evidence that shear-induced Nrf2 regulates HO-1 expression via binding to the ARE in the promoter region, and this regulation involves $\mathrm{PI} 3 \mathrm{~K}$ and ROS.

\section{Conclusion}

In the present study, we examined the regulation of shear stress on Nrf2 in HUVECs. We demonstrated that a laminar shear stress of 12 dyne/ $\mathrm{cm}^{2}$ induced $\mathrm{Nrf} 2$ nuclear 
translocation, and we found that PI3K, PKC, and ROS, but not MAPKs (p38 and JNK), were involved in the signaling pathway. We also found that shear stress increased the ARE-binding activity of Nrf2 and HO-1 expression. HO-1 has been shown to have remarkable antioxidant abilities and is responsible for diverse protective functions against diseases such as atherosclerosis. Our data suggest that the atheroprotective role of laminar shear stress is partly attributed to Nrf2 activation which results in ARE-mediated gene transcription, including $\mathrm{HO}-1$ gene expression, which is beneficial to the cardiovascular system.

\section{Abbreviations}

ARE: antioxidant response element; ECs: endothelial cells; eNOS: endothelial nitric oxide synthase; HO-1: heme-oxygenase 1; HUVECs: human umbilical vein endothelial cells; MAPKs: mitogen-activated protein kinases; NAC: N-acetyl cysteine; NO: nitric oxide; Nrf2: nuclear factor erythroid 2-related factor 2; PI3K: phosphatidylinositol 3-kinase; PKC: protein kinase C; ROS: reactive oxygen species.

\section{Competing interests}

The authors declare that they have no competing interests.

\section{Authors' contributions}

$\mathrm{CYH}$ and $\mathrm{HYH}$ contributed equally to this study. CYH and HYH designed and performed the experiments, participated in the discussion of the results, and drafted part of the manuscript. WYW performed the inhibitor experiments and participated in the discussion of the results. CAL performed the EMSA experiments, participated in the discussion of the results, and helped to draft part of the manuscript. YCT participated in the experimental design and discussion of the results, and helped to draft part of the manuscript. YJC coordinated the experiments and participated in the discussion of the results. DLW co-conceived and co-designed the study, participated in the experimental design and interpretation of the results, reviewed and helped to revise the manuscript. HJH conceived and designed the study and the experiments, coordinated the execution of the study, interpreted the results, wrote the manuscript and also revised it. All authors read and approved the final manuscript.

\section{Acknowledgements}

The authors sincerely thank Mr. Da-Lin Lai for performing the RT-PCR analysis, Mr. Yu-Chi Liu for his helpful suggestion and technical assistance, and Mr. Po-Hui Chen for his help with the lay-out of the figures. This study was financially supported by grants from the National Science Council, Taiwan to DLW (NSC96-2752-B-00I-00I-PAE) and to HJH (NSC93-232I-B002-034, NSC94-232I-B-002-016, and NSC95-2320-B-002-052).

\section{References}

I. Traub O, Berk BC: Laminar shear stress: mechanisms by which endothelial cells transduce an atheroprotective force. Arterioscler Thromb Vasc Biol 1998, 18:677-685.
2. Brooks AR, Lelkes PI, Rubanyi GM: Gene expression profiling of human aortic endothelial cells exposed to disturbed flow and steady laminar flow. Physiol Genomics 2002, 9:27-4I.

3. Chen BP, Li YS, Zhao Y, Chen KD, Li S, Lao J, Yuan S, Shyy JY, Chien $S$ : DNA microarray analysis of gene expression in endothelial cells in response to 24-h shear stress. Physiol Genomics 200I, 7:55-63.

4. McCormick SM, Eskin SG, McIntire LV, Teng CL, Lu CM, Russell CG, Chittur KK: DNA microarray reveals changes in gene expression of shear stressed human umbilical vein endothelial cells. Proc Natl Acad Sci USA 200I, 98:8955-8960.

5. McCormick SM, Frye SR, Eskin SG, Teng CL, Lu CM, Russell CG, Chittur KK, Mclntire LV: Microarray analysis of shear stressed endothelial cells. Biorheology 2003, 40:5-II.

6. Chen XL, Varner SE, Rao AS, Grey JY, Thomas S, Cook CK, Wasserman MA, Medford RM, Jaiswal AK, Kunsch C: Laminar flow induction of antioxidant response element-mediated genes in endothelial cells: A novel anti-inflammatory mechanism. J Biol Chem 2003, 278:703-7II.

7. Dimmeler S, Assmus B, Hermann C, Haendeler J, Zeiher AM: Fluid shear stress stimulates phosphorylation of Akt in human endothelial cells: involvement in suppression of apoptosis. Circ Res 1998, 83:334-34I.

8. Tedgui A, Mallat Z: Anti-inflammatory mechanisms in the vascular wall. Circ Res 200I, 88:877-887.

9. Akimoto S, Mitsumata M, Sasaguri T, Yoshida Y: Laminar shear stress inhibits vascular endothelial cell proliferation by inducing cyclin-dependent kinase inhibitor $\mathrm{p2I}$ (Sdil/Cipl/ Wafl). Circ Res 2000, 86: $185-190$.

10. Lin K, Hsu PP, Chen BP, Yuan S, Usami S, Shyy JY, Li YS, Chien S: Molecular mechanism of endothelial growth arrest by laminar shear stress. Proc Natl Acad Sci USA 2000, 97:9385-9389.

II. Hojo Y, Saito Y, Tanimoto T, Hoefen RJ, Baines CP, Yamamoto K, Haendeler J, Asmis R, Berk BC: Fluid shear stress attenuates hydrogen peroxide-induced c-Jun NH2-terminal kinase activation via a glutathione reductase-mediated mechanism. Circ Res 2002, $91: 7|2-7| 8$.

12. Ni CW, Hsieh HJ, Chao YJ, Wang DL: Shear Flow Attenuates Serum-induced STAT3 Activation in Endothelial Cells. J Biol Chem 2003, 278:19702-19708.

13. Ni CW, Hsieh HJ, Chao YJ, Wang DL: Interleukin-6-induced JAK2/STAT3 signaling pathway in endothelial cells is suppressed by hemodynamic flow. Am J Physiol Cell Physiol 2004, 287:C77I-C780.

14. Surapisitchat J, Hoefen RJ, Pi X, Yoshizumi M, Yan C, Berk BC: Fluid shear stress inhibits TNF-alpha activation of JNK but not ERK I/2 or $\mathrm{p} 38$ in human umbilical vein endothelial cells: Inhibitory crosstalk among MAPK family members. Proc Natl Acad Sci USA 200I, 98:6476-648I.

15. Go YM, Park H, Maland MC, Darley-Usmar VM, Stoyanov B, Wetzker $\mathrm{R}$, Jo H: Phosphatidylinositol 3-kinase gamma mediates shear stress-dependent activation of JNK in endothelial cells. Am J Physiol 1998, 275: HI898-HI904.

16. Dimmeler S, Fleming I, Fisslthaler B, Hermann C, Busse R, Zeiher AM: Activation of nitric oxide synthase in endothelial cells by Akt-dependent phosphorylation. Nature 1999, 399:601-605.

17. Fulton D, Gratton JP, McCabe TJ, Fontana J, Fujio Y, Walsh K, Franke TF, Papapetropoulos A, Sessa WC: Regulation of endotheliumderived nitric oxide production by the protein kinase Akt. Nature 1999, 399:597-60I.

18. Chiu JJ, Wung BS, Hsieh HJ, Lo LW, Wang DL: Nitric oxide regulates shear stress-induced early growth response-I. Expression via the extracellular signal-regulated kinase pathway in endothelial cells. Circ Res 1999, 85:238-246.

19. Kotamraju S, Tampo Y, Keszler A, Chitambar CR, Joseph J, Haas AL, Kalyanaraman $B$ : Nitric oxide inhibits $\mathbf{H}_{2} \mathrm{O}_{2}$-induced transferrin receptor-dependent apoptosis in endothelial cells: Role of ubiquitin-proteasome pathway. Proc Natl Acad Sci USA 2003, 100:10653-10658.

20. Ni CW, Wang DL, Lien SC, Cheng J], Chao YJ, Hsieh HJ: Activation of PKC-epsilon and ERKI/2 participates in shear-induced endothelial MCP-I expression that is repressed by nitric oxide. J Cell Physiol 2003, 1 95:428-434.

21. Wung BS, Cheng JJ, Shyue SK, Wang DL: NO modulates monocyte chemotactic protein-I expression in endothelial cells 
under cyclic strain. Arterioscler Thromb Vasc Biol 200I, 21:194I-1947.

22. Dimmeler S, Hermann C, Galle J, Zeiher AM: Upregulation of superoxide dismutase and nitric oxide synthase mediates the apoptosis-suppressive effects of shear stress on endothelial cells. Arterioscler Thromb Vasc Biol 1999, 19:656-664.

23. Motohashi H, O'Connor T, Katsuoka F, Engel JD, Yamamoto M: Integration and diversity of the regulatory network composed of Maf and CNC families of transcription factors. Gene 2002, 294: $1-12$.

24. Itoh K, Chiba T, Takahashi S, Ishii T, Igarashi K, Katoh $\mathrm{Y}$, Oyake $\mathrm{T}$, Hayashi N, Satoh K, Hatayama I, Yamamoto M, Nabeshima Y: An Nrf2/small Maf heterodimer mediates the induction of phase II detoxifying enzyme genes through antioxidant response elements. Biochem Biophys Res Commun 1997, 236:313-322.

25. Alam J, Stewart D, Touchard C, Boinapally S, Choi AM, Cook JL: Nrf2, a Cap'n'Collar transcription factor, regulates induction of the heme oxygenase-I gene. I Biol Chem 1999, 274:2607|-26078.

26. McMahon M, Itoh K, Yamamoto M, Chanas SA, Henderson C], McLellan LI, Wolf CR, Cavin C, Hayes JD: The Cap'n'Collar basic leucine zipper transcription factor Nrf2 (NF-E2 p45-related factor 2) controls both constitutive and inducible expression of intestinal detoxification and glutathione biosynthetic enzymes. Cancer Res 2001, 61:3299-3307.

27. Chan K, Kan YW: Nrf2 is essential for protection against acute pulmonary injury in mice. Proc Natl Acad Sci USA 1999, 96:1273I-12736.

28. Enomoto A, Itoh K, Nagayoshi E, Haruta J, Kimura T, O'Connor T, Harada T, Yamamoto M: High sensitivity of Nrf2 knockout mice to acetaminophen hepatotoxicity associated with decreased expression of ARE-regulated drug metabolizing enzymes and antioxidant genes. Toxicol Sci 200I, 59:169-177.

29. Chen XL, Dodd G, Thomas S, Zhang X, Wasserman MA, Rovin BH, Kunsch C: Activation of Nrf2/ARE pathway protects endothelial cells from oxidant injury and inhibits inflammatory gene expression. Am J Physiol Heart Circ Physiol 2006, 290:HI862-HI870.

30. Itoh K, Wakabayashi N, Katoh Y, Ishii T, Igarashi K, Engel JD, Yamamoto M: Keap I represses nuclear activation of antioxidant responsive elements by Nrf2 through binding to the amino-terminal Neh2 domain. Genes Dev 1999, 13:76-86.

31. Itoh K, Wakabayashi N, Katoh Y, Ishii T, O'Connor T, Yamamoto M: Keap I regulates both cytoplasmic-nuclear shuttling and degradation of Nrf2 in response to electrophiles. Genes Cells 2003 8:379-391.

32. McMahon M, Itoh K, Yamamoto M, Hayes JD: Keap I-dependent Proteasomal Degradation of Transcription Factor Nrf2 Contributes to the Negative Regulation of Antioxidant Response Element-driven Gene Expression. J Biol Chem 2003, 278:21592-21600.

33. Dinkova-Kostova AT, Massiah MA, Bozak RE, Hicks RJ, Talalay P. From the Cover: Potency of Michael reaction acceptors as inducers of enzymes that protect against carcinogenesis depends on their reactivity with sulfhydryl groups. Proc Natl Acad Sci USA 200I, 98:3404-3409.

34. Kim YC, Yamaguchi Y, Kondo N, Masutani H, Yodoi I: Thioredoxindependent redox regulation of the antioxidant responsive element (ARE) in electrophile response. Oncogene 2003, 22: $1860-\mid 865$

35. Buckley BJ, Marshall ZM, Whorton AR: Nitric oxide stimulates Nrf2 nuclear translocation in vascular endothelium. Biochem Biophys Res Commun 2003, 307:973-979.

36. Kang KW, Lee SJ, Park JW, Kim SG: Phosphatidylinositol 3-kinase regulates nuclear translocation of NF-E2-related factor 2 through actin rearrangement in response to oxidative stress. Mol Pharmacol 2002, 62: 1001-1010.

37. Nakaso $K$, Yano $H$, Fukuhara $Y$ Takeshima $T$, Wada-lsoe $K$ Nakashima K: PI3K is a key molecule in the Nrf2-mediated regulation of antioxidative proteins by hemin in human neuroblastoma cells. FEBS Lett 2003, 546:181-184.

38. Huang HC, Nguyen T, Pickett CB: Phosphorylation of Nrf2 at Ser-40 by protein kinase $C$ regulates antioxidant response element-mediated transcription. I Biol Chem 2002, 277:42769-42774.

39. Bloom DA, Jaiswal AK: Phosphorylation of Nrf2S40 by PKC in response to antioxidants leads to the release of $\mathrm{Nrf2}$ from
INrf2 but not required for Nrf2 stabilization/accumulation in the nucleus and transcriptional activation of ARE-mediated NQOI gene expression. J Biol Chem 2003, 278:44675-44682.

40. Alam J, Wicks C, Stewart D, Gong P, Touchard C, Otterbein S, Choi AM, Burow ME, Tou J: Mechanism of heme oxygenase-I gene activation by cadmium in MCF-7 mammary epithelial cells. Role of p38 kinase and Nrf2 transcription factor. I Biol Chem 2000, 275:27694-27702.

4I. Zipper LM, Mulcahy RT: Inhibition of ERK and p38 MAP kinases inhibits binding of Nrf2 and induction of GCS genes. Biochem Biophys Res Commun 2000, 278:484-492.

42. Kang KW, Lee SJ, Kim SG: Molecular mechanism of nrf2 activation by oxidative stress. Antioxid Redox Signal 2005, 7:1664-1673.

43. Srisook K, Kim C, Cha YN: Molecular mechanisms involved in enhancing HO-I expression: de-repression by heme and activation by Nrf2, the "one-two" punch. Antioxid Redox Signal 2005, 7:1674-1687.

44. Hosoya T, Maruyama A, Kang MI, Kawatani Y, Shibata T, Uchida K, Warabi E, Noguchi N, Itoh K, Yamamoto M: Differential responses of the Nrf2-Keapl system to laminar and oscillatory shear stresses in endothelial cells. J Biol Chem 2005, 280:27244-27250.

45. Hsieh HJ, Cheng CC, Wu ST, Chiu JJ, Wung BS, Wang DL: Increase of reactive oxygen species (ROS) in endothelial cells by shear flow and involvement of ROS in shear-induced c-fos expression. J Cell Physiol 1998, 175: I56-162.

46. De Keulenaer GW, Chappell DC, Ishizaka N, Nerem RM, Alexander RW, Griendling KK: Oscillatory and steady laminar shear stress differentially affect human endothelial redox state: role of a superoxide-producing NADH oxidase. Circ Res 1998, 82:1094-II0I.

47. Maines MD: The heme oxygenase system: a regulator of second messenger gases. Annu Rev Pharmacol Toxicol 1997, 37:517-554

48. Morse D, Choi AM: Heme oxygenase-I: the "emerging molecule" has arrived. Am J Respir Cell Mol Biol 2002, 27:8-16.

49. Hsieh HJ, Cheng CC: Responses of Endothelial Cells to Laminar or Disturbed Flow. Bull Coll Eng NTU 1996, 68:107-I 20.

50. Lee JM, Moehlenkamp JD, Hanson JM, Johnson JA: Nrf2-dependent activation of the antioxidant responsive element by tertbutylhydroquinone is independent of oxidative stress in IMR32 human neuroblastoma cells. Biochem Biophys Res Commun 200I, 280:286-292

51. Moi P, Chan K, Asunis I, Cao A, Kan YW: Isolation of NF-E2related factor 2 (Nrf2), a NF-E2-like basic leucine zipper transcriptional activator that binds to the tandem NF-E2 API repeat of the beta-globin locus control region. Proc Nat Acad Sci USA 1994, 91 :9926-9930.

52. Nguyen T, Sherratt PJ, Nioi P, Yang CS, Pickett CB: Nrf2 controls constitutive and inducible expression of ARE-driven genes through a dynamic pathway involving nucleocytoplasmic shuttling by Keap I. J Biol Chem 2005, 280:32485-32492.

53. Lee JM, Hanson JM, Chu WA, Johnson JA: Phosphatidylinositol 3kinase, not extracellular signal-regulated kinase, regulates activation of the antioxidant-responsive element in IMR-32 human neuroblastoma cells. J Biol Chem 200I, 276:200I I-200I6.

54. Kim BC, Jeon WK, Hong HY, Jeon KB, Hahn JH, Kim YM, Numazawa $\mathrm{S}$, Yosida T, Park EH, Lim CJ: The anti-inflammatory activity of Phellinus linteus (Berk. \& M.A. Curt.) is mediated through the PKCdelta/Nrf2/ARE signaling to up-regulation of heme oxygenase-I. J Ethnopharmacol 2007, I I 3:240-247.

55. Chen C, Kong AN: Dietary chemopreventive compounds and ARE/EpRE signaling. Free Radic Biol Med 2004, 36: I505-I5 I6.

56. Owuor ED, Kong AN: Antioxidants and oxidants regulated signal transduction pathways. Biochem Pharmacol 2002, 64:765-770.

57. Kuchan MJ, Frangos JA: Role of calcium and calmodulin in flowinduced nitric oxide production in endothelial cells. Am J Physiol 1994, 266: C628-C636.

58. Noris M, Morigi M, Donadelli R, Aiello S, Foppolo M, Todeschini M, Orisio $S$, Remuzzi G, Remuzzi A: Nitric oxide synthesis by cultured endothelial cells is modulated by flow conditions. Circ Res 1995, 76:536-543.

59. Kataoka K, Handa $\mathrm{H}$, Nishizawa M: Induction of cellular antioxidative stress genes through heterodimeric transcription factor Nrf2/small Maf by antirheumatic gold(I) compounds. J Biol Chem 200I, 276:34074-3408I. 
60. Eggler AL, Liu G, Pezzuto JM, van Breemen RB, Mesecar AD: Modifying specific cysteines of the electrophile-sensing human Keap I protein is insufficient to disrupt binding to the Nrf2 domain Neh2. Proc Natl Acad Sci USA 2005, I 02: 10070-I0075.

61. Hong F, Sekhar KR, Freeman ML, Liebler DC: Specific patterns of electrophile adduction trigger KeapI ubiquitination and Nrf2 activation. J Biol Chem 2005, 280:3।768-3।775.

62. Wakabayashi N, Dinkova-Kostova AT, Holtzclaw WD, Kang MI, Kobayashi A, Yamamoto M, Kensler TW, Talalay P: Protection against electrophile and oxidant stress by induction of the phase 2 response: Fate of cysteines of the Keap I sensor modified by inducers. Proc Natl Acad Sci USA 2004, I 0 I:2040-2045.

63. Hancock JT, Desikan R, Neill SJ: Role of reactive oxygen species in cell signalling pathways. Biochem Soc Trans 200I, 29:345-350.

64. Li JM, Shah AM: Endothelial cell superoxide generation: regulation and relevance for cardiovascular pathophysiology. Am J Physiol Regul Integr Comp Physiol 2004, 287:R I0I 4-R I030.

Publish with Bio Med Central and every scientist can read your work free of charge

"BioMed Central will be the most significant development for disseminating the results of biomedical research in our lifetime. "

Sir Paul Nurse, Cancer Research UK

Your research papers will be:

- available free of charge to the entire biomedical community

- peer reviewed and published immediately upon acceptance

- cited in PubMed and archived on PubMed Central

- yours - you keep the copyright

Submit your manuscript here:

http://www.biomedcentral.com/info/publishing_adv.asp
BiolMedcentral 